\title{
Internet of Value: A Risky Necessity
}

\author{
Paolo Tasca* \\ University College London Centre for Blockchain Technologies, London, United Kingdom
}

Keywords: Internet of Value, blockchain, datafication, dematerialization, platformization, governance risk, systemic risk, privacy risk

It is indisputable that a fundamental change is underway in the global economy. As ever, there are observable markers of a deep, structural transformation taking place. And as with earlier transformations, the Internet lies at its core. On the one hand, it is clear that the trend toward "digital" transformation, facilitated by the rapid development of the distributed ledger technology, is impacting not only information goods but also physical goods. It is gathering pace across a wide range of industry sectors, from personal banking to hospitality and the apparel industry, to name a few.

However, this alone does not fully capture the scale of the underlying structural shift from an industrial society based on material things to an information society populated by digital things and digital citizens interconnected in a new world of Internet of Value (IoV), where value is exchanged as freely and easily as information (OpenMarkets, 2015).

In this Editorial, I argue that the blooming of the Internet of Value is a necessary journey that we need to take in order to accommodate the unfolding of four long-term mega socio-techno trends: datafication, dematerialization, platformization, and social and resources value awareness.

OPEN ACCESS

Edited by:

Olinga Taeed,

Centre for Citizenship, Enterprise and Governance, United Kingdom

Reviewed by:

Avishek Nag,

University College Dublin, Ireland Haider M. Al-Khateeb,

University of Wolverhampton,

United Kingdom

*Correspondence:

Paolo Tasca

p.tasca@ucl.ac.uk

Specialty section:

This article was submitted to Fourth Industrial Revolution,

a section of the journal

Frontiers in Blockchain

Received: 06 March 2020

Accepted: 23 July 2020

Published: 15 September 2020

Citation:

Tasca P (2020) Internet of Value: A Risky Necessity.

Front. Blockchain 3:39.

doi: 10.3389/fbloc.2020.00039
Unfortunately, as pictured in Figure 1, this journey will not be without obstacles. Systemic risk, governance risk, privacy risk, and social welfare risk are four major sources of risk that we must mitigate in order to build an open, accessible, and secure Internet of Value for an equitable global economy.

\section{THE INTERNET OF VALUE DRIVING FORCES}

I identify four key socio-techno trends underpinning the transition of our society to the Internet of Value. In this transition, IoV emerges not as a goal but as necessary infrastructure to enable these trends to unfold their potentialities fully.

The first trend is datafication.

Datafication is the transformation of social action into digitized information (MayerSchönberger and Cukier, 2013).

In recent years, the amount of data available has increased at an unprecedented pace. In 2020, every person generates 1.7 MB in just a second, and Internet users as a whole generate about 2.5 EB of data each day (Po et al., 2020). Regardless of whether we are aware of it or not, each of us every single day leaves our fingerprints in cyberspace. Every simple thing we do (from downloading a report, to ordering a pizza online, or to access the gym with our PIN) is potentially captured by someone and stored in servers somewhere in the cloud. This process of datafication is turning many aspects of our life into data, with value beyond their immediate utility. At one level, data that relate to our habits, routines, and other aspects of our lives have value in and of themselves by enabling consumers to interact with each other and the market in novel ways. According to World Economic Forum (WEF), we will produce more data in the next 3 years (2020-2022) than what we did in the last 10 years (2010-2019) (Gast, 2020).

Additionally, we are implanting Internet connectivity into our everyday environment-through smart devices, we watch, wear, and interact with-as a way of generating ever-greater volumes of data for our own consumption. This is the "Internet of Things" (or "IoT"), and it is estimated that 


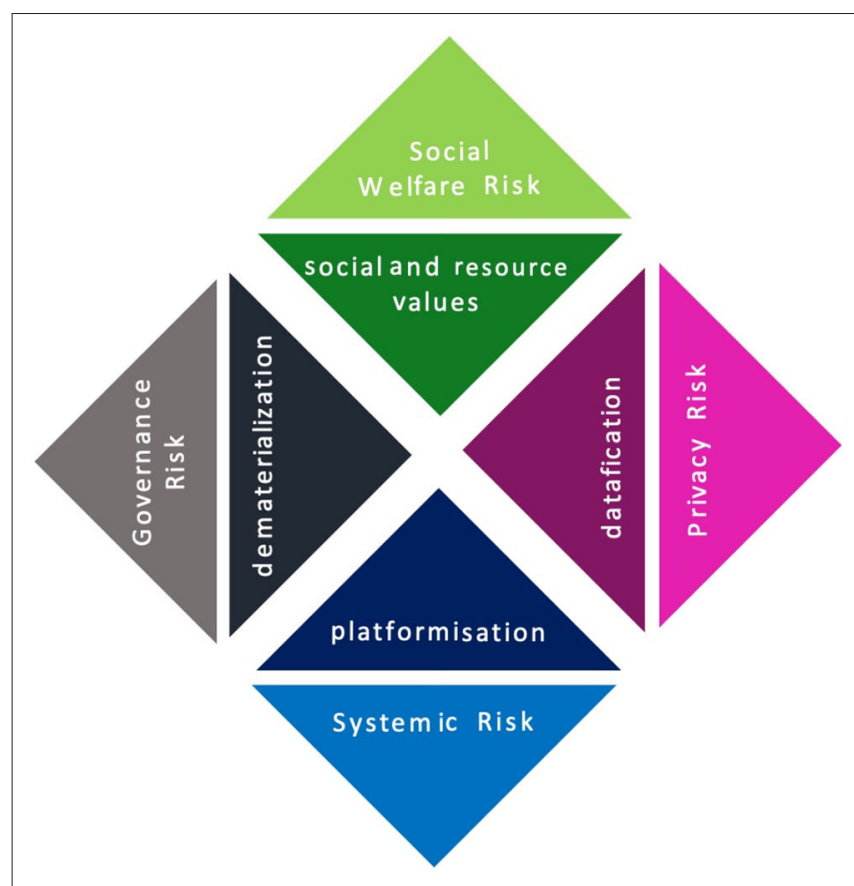

FIGURE 1 | Four megatrends underpinning the Internet of Value and four major sources of risk.

by the end of 2020, the number of interconnected devices will exceed 50 billion; by 2022, 1 trillion networked sensors will be embedded in the world around us, with up to 45 trillion in 20 years ${ }^{1}$. An abundance of data enables new types of services to be tailored and delivered to consumers, whose needs, desires, and circumstances are-through the analysis of data-better understood than ever before.

Certainly, measuring the amount of data that we generate today and the number of interconnected devices is not an exact science $^{2}$. However, what is important is the magnitude of this phenomenal trend that is turning many aspects of our lives into information as a new form of value. Through the process of datafication, information technology lets us measure, track, and exchange ever more types of value at ever-smaller increments. It is essential, therefore, to build an interconnected network of value exchange linking all of the things and all the individuals at the lowest possible transaction cost.

The second trend is dematerialization.

When we talk about dematerialization, we refer to the longterm process started a few decades ago of reduction in the material used in products. Dematerialization is not only about digital goods but also physical goods. Physical goods have seen an increasing shift from tangible toward intangible components. Soft things like intelligence are embedded in hard things, making physical goods increasingly behave more similarly to software.

\footnotetext{
${ }^{1}$ See, https://www.huffpost.com/entry/cisco-enterprises-are-leading-the-internetof-things_b_59a41fcee4b0a62d0987b0c6.

${ }^{2}$ See, for example https://www.weforum.org/agenda/2019/04/how-much-data-isgenerated-each-day-cf4bddf29f/.
}

Digital technology accelerates the dematerialization, boosting the migration from a production economy to the emerging service economy. As such, all spheres of the economy become redefined away from the conception of units of productionwhich underpinned our economic systems in past centuriestoward the more fluid concept of the exchange of value enabled by the IoV. A service economy is about value delivered. A service is an exchange of value-you do not get the product; you just get its function and the value that it delivers. As such, during this transition phase, the principle of "ownership of" - around which we built the capitalism markets-is put aside in favor of the more adequate principle of "access to." Indeed, ownership is casual, and a transaction occurs only once. Instead, a service economy is based on subscriptions to services that are characterized by an ongoing stream of data and transactions that are better supported if we get seamlessly ubiquitous access to the IoV.

The third trend is platformization.

Platformization is the establishment of digital platforms for various economic, governmental, and cultural activities (Poell et al., 2019).

In recent years, we have witnessed the proliferation of technology-enabled platforms supported by computerand network-based information and communications technologies (ICT), which match both demand and supply of underutilized assets and allow everybody to be connected and disseminate/exchange information and value. Here, I refer to the third generation of platform business models: multiside marketplaces where a multitude of buyers and sellers meet and exchange any type of digital or digitized goods and value. Examples include data exchange platform such as Dawex (dawex.com) and digital security marketplace such as Securitize (securitize.io). However, platformization goes beyond digital goods and includes also idle physical goods, the utility of which can be exchanged among peers. Think about the emerging car-sharing platforms like Streetcar, ShareNow, Zipcar, or the platforms that allow households to let out their underutilized space like AirbnB and HomeAway.

This is a global marketplace of different types of interconnected platforms (platforms that depend on other platforms through mutually beneficial connections) that evolve in a Darwinian fashion by matching different needs and purposes. A growing component of our economy is occupied by platform business models that, for the amount of value generated, are gradually displacing linear business models ${ }^{3}$. In this "platformization," consumers are closer to the producers, and in fact, consumers often act as producers or what the futurist Alvin Tafler called the "prosumers." Millions of consumers become prosumers. They exchange value in lateral networks at near-zero marginal costs. The difference between the linear business models and the platform is that the linear business models scale up by investing in internal resources and inventories. Instead, platform business models do not directly create and control inventory. They scale up by investing in their networks. The larger their network, the greater their value.

${ }^{3}$ More than $60 \%$ of today's billion-dollar "unicorn" start-ups is composed of platform businesses (Cusumano et al., 2020). 
Platformization fits well with the new consumers' habits of digital natives that are open to community sharing models from digital to physical goods. Thus, platformization better interprets the needs of these people by creating a sort of "technological socialism," which elevates both the individual and the group at once.

The fourth trend is social and resources value.

Social and resources value quantifies the relative importance one places on the changes experienced in their lives, such as an increase in confidence, or moving to a neighborhood with a community park (Social Value UK, 2020).

In the last centuries, capitalism has led to the erosion and loss of social and environmental capital in exchange for higher private profits. We have eroded the overall value of social and public goods (think about environmental pollution, for example) in favor of the value of private and personal goods. It is now recognized that this capitalist model is broken and that it cannot continue with the same principles as in the past. A growing number of people and companies are not willing anymore to compromise social capital and natural resources for higher profits. This can be seen most clearly in the demand for assets tied in measurable ways to the quality of life. There is a growing awareness of their value, and people place a higher demand for quality of life, which of course engenders a broader spectrum of values beyond economic utility. Over the past decades, we have increasingly begun the process of tracking and accounting for different forms of value whether these are green bonds, social impact bonds, company loyalty schemes, carbon accounting, or a multiplicity of other forms. The IoV becomes, therefore, the infrastructure that allows us to smoothly exchange this growing number of different types of social and environmental values between companies and people.

We conclude by asserting that the IoV is the inevitable outcome of these four driving factors. At its core, IoV is the information network that facilitates the transfer of value (often and increasingly) without the involvement or intermediation of a third party. It is exponentially characterized by hyperconnectivity. Almost by design, dematerialization and platformization require economic actors in ever more significant numbers to exchange data and value across networks. As in all markets, trust between participants is essential-and we would, therefore, expect that the IoV will emerge as interconnected networks of trust. Distributed ledger technologies are a novel way of providing this trust, and other trust-providing technologies will likely emerge as IoV takes shape in the next few years.

\section{THE INTERNET OF VALUE RISKS}

The emergence of the IoV is not without risk. With the increasing economic importance and value of data comes new trade-offs in respect of accountability, responsibility, ownership, privacy, and security. I identify four major sources of risks in the IoVbased economy.

The first risk is systemic risk.
Systemic risk refers to the risk of a failure of an entire system as opposed to the malfunction of individual parts (CFA Institute, 2020).

Certainly, systemic risk increases with the number of interdependencies between numerous and diverse networks of trust, which characterize the current globalized economy (Battiston et al., 2012). This is particularly true for financial networks where banks not only hold overlapping portfolios but also hold claims on each other's liabilities. In this setting, a bank's payoff not only depends on the bank's own financial condition but also on the financial conditions of the other banks to which it is interconnected. Thus, individual default risks are likely to be spread over the neighbors in the network (Tasca et al., 2017). For example, the UK interbank network was highly concentrated, exhibiting fat-tailed distributions of linkages and loan sizes at the time of the 2008-2009 global financial crisis (Bank of England, 2009). Consequently, the UK suffered a severe recession (Economic Social Research Council, 2015). Such network systems are characterized with tipping points, where shocks have the rippling effect, and a few failing nodes can cause the entire system to collapse (Gai and Kapadia, 2019).

We do not have data to measure the systemic risk in the Internet of Value because it is still in its infancy ${ }^{4}$. However, we can learn from other interconnected systems like the financial system, and we can derive some properties that can be used as a reference to measure the potential risks emerging in the IoV. History teaches us that increasing interconnection in complex financial systems is characterized by emergent properties that are not observable at the microlevel and higher fragility that can lead to cascading defaults and failures. Networks exhibit a trade-off between efficiency and robustness to attacks. The network topology, which is desirable for efficiency gains, does not generally match the one that is preferable in terms of robustness against attacks (Trajanovski et al., 2013).

Finally, when we talk about the IoV, we need to ask ourselves if the IoV would be considered a public good and if this public good would be managed by private entities that pursue private profits. In such a case, the IoV would be a private international network that would need-in case of disaster-to be backed by taxpayers because it would be too big to fail. Should we need to consider a public bailout of a privately managed system? These are the questions that we need to answer to properly design a stable, robust, and efficient IoV architecture. My recommendation is that the IoV architecture should wisely balance both the public and private interests.

The second risk is governance risk.

Governance risk is associated with accountability, responsibility, and ownership, which becomes critical for the viability and stability of the entire digital IoV ecosystem. Building a common understanding of rights and responsibilities, therefore, becomes essential.

\footnotetext{
${ }^{4}$ For the Ethereum Enterprise Alliance, the criteria to join the BoD are not specified. You can join only class B, C, and D. Class A is locked. In Hyperledger, the governing board adopts and maintains the rules. Members are chosen by Premier Members. This means that they must pay $\$ 250 \mathrm{k} /$ year plus the membership to the Linux Foundation, which cost either $\$ 500 \mathrm{k} /$ year or $\$ 100 \mathrm{k} /$ year.
} 
Here, there exists a trade-off between private centralized governance models and public decentralized and anonymous governance models. Generally, private models are proposed by industry-grade network providers, while public governance models are familiar to open source network systems. In the case of the IoV supported by distributed ledger technologies, private governance solutions are proposed by Hyperledger or the Ethereum Enterprise Alliance, to name a few.

Instead, decentralized public solutions are provided by Bitcoin, Tezos, and the like. Indeed, we observe that not only private governance models are centralized by design but also public models-that shall be decentralized-indeed tend to become centralized over time. For example, the top 5 mining ETH pools secure about $80 \%$ of the transactions in the ledger, $20 \%$ of ETH's core code was written by a single coder, $30 \%$ of Bitcoin's core code was written by a single coder, and $50 \%$ of all comments for Bitcoin Improvement Proposals (BIPs) come from the $0.3 \%$ of commenters. Given these dualities, we face a conundrum: either we let networks of trust be run by centralized but accountable trust providers or we keep direct "control" of our data via a synthetic-trust machine replication run by a small group of anonymous people who could easily go rogue (Tasca, 2018, The Hope and Betrayal of Blockchain, New York Times, https://www.nytimes.com/2018/12/04/opinion/blockchain-

bitcoin-technology- revolution.html).

When we talk about governance models of the IoV, we cannot avoid considering the risk arising from the lack of interoperability between different networks of trust that will need to exchange data and value between them. In particular, interoperability constitutes the point at which tensions emerge between three distinct intentions for blockchain technology as regulatory technology, business/economic infrastructure, and the model of social organization. If "code is law," then the interoperability between blockchains is not a mere problem of standards; it is a problem of norms that should be addressed with reciprocal recognition between sovereign powers in their own space (Tasca and Piselli, 2019).

The third risk is social welfare risk.

Social welfare risk concerns the decrease in well-being of the entire society due to, e.g., growing inequality or inadequate supply of infrastructure vis-a-vis increasing demand.

While the promise of the IoV is transforming the global economic landscape by reducing search and transaction costs, which are particularly beneficial in emerging economies, how

\section{REFERENCES}

AICPA. (2020). Privacy Risk Management. Available online at: https://www. aicpa.org/interestareas/informationtechnology/resources/privacy-riskmanagement.html (accessed June 13, 2020)

Bank of England (2009). The role of Macroprudential Policy.

Battiston, S., Puliga, M., Kaushik, R., Tasca, P., and Caldarelli, G. (2012). Debtrank: Too central to fail? financial networks, the fed and systemic risk. Sci. Rep. 2:541. doi: $10.1038 /$ srep00541

CFA Institute (2020). Systemic Risk. Available online at: https://www. cfainstitute.org/en/advocacy/issues/systemic-risk (accessed June 13, 2020). exactly those who are not fully connected to the Internet (still 3.37 billion as of today) would reap these benefits remains unclear. Therefore, to mitigate inequality and the social welfare risk, we need to expand the access to the Internet primarily in those areas where precisely the benefits of the IoV are expected to be most promising.

The fourth risk is privacy risk.

Private risk is associated with the uncontrolled disclosure of personal information (AICPA., 2020).

This is the risk of being captured by the rhetoric of empowering people (advocacy and emancipation-see banking the unbanked) and the ability to trade seamlessly and be connected, where indeed the hidden intent is to feed capitalism with every aspect of every human experience (i.e., our data). This is the risk posed by the so-called surveillance capitalism (see Zuboff, 2019). We cannot assume that technology underpinning the IoV is isolated from the economy and society. Technology is always an expression of economic objectives that direct it into action.

We, therefore, propose a privacy-enabling electronic value exchange. There must be a plausible means by which an individual seeking to remit any digital/digitized assets or other value in the IoV can be assured, without the need for special technology, special dispensation, or third-party trust of any kind, that the metadata associated with the transaction, including time, location, counterparty, and other transaction details, would not be associated with any information that might be used to identify the individual. These privacy-enhancing technologies should be put in place to protect from users from profiling and monitoring.

To conclude, I would say that it is romantic and simple to imagine a dystopian future and then ask the tech leaders to stop innovating and stop building the IoV architecture that will be necessary to shape our economy in the next decades.

It is, instead, much harder to promote those institutional and personal adjustments required in this complex and fast-changing world of liquid modernity where we find ourselves. I, therefore, invite all the operators and stakeholders who are building the new digital economy to work together to build an open, accessible, and secure IoV for an equitable global economy.

\section{AUTHOR CONTRIBUTIONS}

The author confirms being the sole contributor of this work and has approved it for publication.

Cusumano, M. A., Yoffie, D. B., and Gawer, A. (2020). The Future of Platforms MIT Sloan Management Review. Available online at: https://sloanreview.mit. edu/article/the-future-of-platforms/ (accessed June 13, 2020).

Economic and Social Research Council (2015). The Global Financial Crisis.

Gai, P., and Kapadia, S. (2019). Networks and systemic risk in the financial system. Oxford Rev. Econ. Policy 35, 586-613. doi: 10.1093/oxrep/grz023

Gast, A. (2020). Why We Need to Talk About Big Data, WEF Annual Meeting. Available online at: https://www.weforum.org/agenda/2020/01/privacy-in-aworld-of-ai-and-big-data/

Mayer-Schönberger, V., and Cukier, K. (2013). Big Data : A Revolution that Will Transform How We Live, Work and Think. New York, NY: Houghton Mifflin Harcourt. 
OpenMarkets (2015). Ripple Labs And The Internet of Value. CME GROUP. Available online at: https://openmarkets.cmegroup.com/10381/what-is-aninternet-of-value. (accessed June 12, 2020)

Po, L., Bikakis, N., Desimoni, F., and Papastefanatos, G. (2020). Linked data visualization: techniques, tools, and big data. Synthesis Lect. Semantic Web 10, 4-6. doi: 10.2200/S00967ED1V01Y201911WBE019

Poell, T., Nieborg, D., and van Dijck, J. (2019). Platformisation. Internet Policy Rev. 8, 1-2. doi: 10.14763/2019.4.1425

Social Value UK (2020). What is Social Value? Available online at: http://www. socialvalueuk.org/what-is-social-value/ (accessed June 13, 2020).

Tasca, P. (2018) The Hope and Betrayal of Blockchain, New York Times, Available online at: https://www.nytimes.com/2018/12/04/opinion/blockchain-bitcointechnology- $\sim$ revolution.html)

Tasca, P., Battiston, S., and Deghi, A. (2017). Portfolio diversification and systemic risk in interbank networks. J. Econ. Dynamics Control 82, 96-124. doi: $10.1016 /$ j.jedc.2017.01.013

Tasca, P., and Piselli, R. (2019). "The blockchain paradox," in Regulating Blockchain: Techno-Social and Legal Challenges, eds P. Hacker, I. Lianos,
G. Dimitropoulos, and S. Eich (Oxford: Oxford University Press). doi: 10.1093/oso/9780198842187.003.0002

Trajanovski, S., Martin-Hernandez, J., Winterbach, W., and Van Mieghem, P. (2013). Robustness envelopes of networks. J. Complex Networks 1, 44-62. doi: 10.1093/comnet/cnt004

Zuboff, S. (2019). The Age of Surveillance Capitalism: The Fight for a Human Future at the New Frontier of Power. London: Profile Books.

Conflict of Interest: The author declares that the research was conducted in the absence of any commercial or financial relationships that could be construed as a potential conflict of interest.

Copyright (c) 2020 Tasca. This is an open-access article distributed under the terms of the Creative Commons Attribution License (CC BY). The use, distribution or reproduction in other forums is permitted, provided the original author(s) and the copyright owner(s) are credited and that the original publication in this journal is cited, in accordance with accepted academic practice. No use, distribution or reproduction is permitted which does not comply with these terms. 